Article

\title{
Effects of Surgical Stress on Serum Cortisol Level: A Comparative Study between Elective and Emergency Surgery
}

\author{
Selimuzzaman SM1, Begum $\mathrm{N}^{2}$, Islam $\mathrm{N}^{3}$, Begum $\mathrm{S}^{4}$
}

The study was designed to observe the effects of surgical stress on serum level of cortisol in patients undergoing surgical treatment and to find out any differences in hormonal response between elective and emergency surgical procedures. A total number of 60 male subjects aged between 18 and 45 years were included in the study. Of them, 20 were healthy control (Group I), 20 underwent elective surgical treatment (Group II) and emergency surgical interventions were applied in rest 20 subjects (Group III). Study Groups were further divided into subgroups A (preoperative samples were collected 1hour before operation), B (postoperative samples were collected 1-hour after the end of the operation) and C (postoperative samples were collected 24-hours after operation).Serum cortisol level was estimated by invitro-immunolytic test.Statistical analysis was done by paired, unpaired ' $\mathrm{t}$ ' test and regression analysis. The preoperative mean serum cortisol concentration in elective surgical cases was almost similar to that of healthy control. On the contrary, in the emergency surgical cases, a significantly increased mean cortisol level were observed (I vs IIIA and IIA vs IIIA; P < 0.05). The serum cortisol concentrations were increased both in elective and emergency surgical cases after operations but the magnitude of rise was more marked in emergency group of patients (IIB vs IIIB; P $<0.05$ ). Therefore, this study reveals that surgical intervention causes increase in serum cortisol which is more marked in emergency procedure.

Key Words: Stress; Cortisol; Surgery

J Bangladesh Soc Physiol. 2007 Dec;(2): 28-33. For author affiliations, see end of text.

http://www.banglajol.info/index.php/JBSP

\section{Introduction}

$\square$ he capability of responding to any noxious or stressful stimulus is one of the most fundamental characteristics of living organisms including the humans. Stress may be produced by administration of anesthetics, injection of insulin (producing hypoglycaemia), infectious diseases, toxins, haemorrhage, traumatic shock, surgical operations, severe burns, exposure to cold, anoxia, muscular exercise, fear, pain, anxiety, anger, frustration, and fatigue etc ${ }^{1}$. At the beginning of surgery Plasma cortisol concentrations increases and its peak in circulation is reached within few hours after surgery. ${ }^{2,3}$ It was found that the magnitude of increase in plasma concentration was generally proportional to the severity of injury. ${ }^{2,4-7}$ Different studies had shown that the increased plasma cortisol concentrations are variable. Thus, elevated concentrations of plasma cortisol were found at one hour after operations ${ }^{8-11}$ and on the first post-operative day. ${ }^{6,9}$ Raised serum cortisol throughout the first post-operative week were observed $^{12}$. On the contrary ${ }^{13}$ nonsignificant increase in serum cortisol concentration after 24 hours of operation were also observed. 
Many researchers of different countries had investigated stress responses due to elective surgical procedures. From available data it is assumed that hormonal response pattern in patients with acute surgical conditions necessitating emergency surgical treatment have not been well investigated. Thus the present study was designed to observe the effects of surgical stress on serum level of cortisol in patients undergoing surgery, both elective, which would be in stress and emergency, which were already in stress. In addition, some factors influencing the stress response were such as duration of operation and stress severity of score were also studied in this group of population.

\section{Methods}

In the present study, a total number of 60 male subjects aged between 18 and 45 years were selected. Study subjects were selected randomly from patients admitted in the Department of Surgery, Dhaka Medical College Hospital (DMCH), Dhaka. Healthy control subjects were selected from friends, relatives and colleagues from personal contact.

Of the subjects, 20 were apparently healthy (Control, Group I), 20 patients underwent elective open abdominal surgery under general anaesthesia., Group II) and 20 patients underwent emergency open abdominal surgery under general anesthesia were included in study groups(group III). Group II and III were further divided as Group IIA and IIIA (pre-operative) whose blood samples were collected 1 hour before operations; Group IIB and IIIB (postoperative) - samples were collected 1 hour after operations and Group IIC and IIIC (postoperative) - blood samples were collected 24 hours after the end of the operation.

Among the admitted patients, subjects with following indications for surgery were included in the study group:

J Bangladesh Soc Physiol. 2007 Dec;(2): 28-33.

\begin{tabular}{lc}
\hline Indication & Number of patients \\
\hline Emergency Surgery & \\
Acute appendicitis & 8 \\
$\quad$ Perforation of gas containing & 12 \\
hollow viscus & \\
Elective Surgery: & \\
$\quad$ Cholelithiasis & 10 \\
Gastric outlet obstruction & 10 \\
\hline
\end{tabular}

Patients suffering from kidney disease, liver disease, diabetes mellitus and other apparent endocrine disorder or taking corticosteriod and drugs that affect serum cortisol levels were excluded from the study.

A modified form of scoring system of surgical stress was adopted after Anand and AnsleyGreen. ${ }^{7}$ Levels of stress were assessed by considering volume of blood loss, extent of superficial trauma, duration of surgery, presence or absence of infection or inflammation, peroperative complication or any supplementary surgical procedure, for example, nasogastric suction, in-situ drainage tube or catheterization. Scoring was done by questioning the treating surgeons immediately after completion of the operations and subsequent follow up. In our scoring system, stress score could vary from as low as 3 to a maximum of 22. Our subjects scored between 7 and 15 .

All the cases were treated by open abdominal surgery under general anaesthesia. None of the patients received any pre-medication. Anaesthesia was induced by intravenous thiopentone sodium at a dose of $4 \mathrm{mg} / \mathrm{kg}$ body weight. Total amount of thiopentone sodium received by the patients varied from 150 to 250 $\mathrm{mg}$. Induction of anaesthesia was immediately followed by endotracheal intubation under intravenous suxamethonium at the dose of 50$90 \mathrm{mg}$. Adequate muscle relaxation was achieved by vecoronium bromide (Norcuron). 'Bain circuit' was used to maintain anaesthesia. 
Anaesthesia was maintained by $0.5 \%$ halothane and nitrous oxide at a rate of $3.5 \mathrm{~L} / \mathrm{min}$. Artificial respiration was controlled manually. $\mathrm{O}_{2}$ was delivered at a rate of 2-3 $\mathrm{L} / \mathrm{min}$. Anaesthesia was reversed by injection neostigmine and atropine at a dose of $2-5 \mathrm{mg}$ and 0.6 to $2.0 \mathrm{mg}$ respectively.

Estimation of serum cortisol was done by invitro enzyme - immunologic test by an automated device using ES300 - Twin software. Statistical analysis was done by paired, unpaired ' $t$ ' test and regression analysis.using SPSS10 software.

\section{Results}

Table I shows that the mean ( \pm SE) serum cortisol concentration in healthy control (368 $\pm 24 \mathrm{nmol} /$ L) was within normal range.

Table - I: Mean ( \pm SE) serum cortisol concentrations in different groups of subjects $(\mathrm{n}=60)$

\begin{tabular}{lcc}
\hline Group & $\mathrm{n}$ & Serum cortisol(nmol/L) \\
\hline I & 20 & $368 \pm 24$ \\
IIA & 20 & $403 \pm 28$ \\
IIB & 20 & $695 \pm 33$ \\
IIC & 20 & $462 \pm 27$ \\
IIIA & 20 & $573 \pm 77$ \\
IIIB & 20 & $847 \pm 63$ \\
IIIC & 20 & $529 \pm 52$ \\
\hline
\end{tabular}

Group I = Healthy control; Group II = Patient undergoing elective surgery; Group III = Patient undergoing emergency surgery. $\mathrm{A}=$ Pre-operative; $\mathrm{B}$ = 1-hour post-operative; $\mathrm{C}=$ 24-hour post-operative. $\mathrm{n}=$ total number of subjects.

In subjects undergoing elective surgical procedures, the mean $( \pm \mathrm{SE})$ serum cortisol concentrations were $403 \pm 28,695 \pm 33$ and 462 $\pm 27 \mathrm{nmol} / \mathrm{L}$ in group IIA (preoperative), group IIB (1-hour post operative) and Group IIC (24hour postoperative) respectively. On the other hand, the preoperative mean $( \pm \mathrm{SE})$ serum cortisol concentration in emergency surgical procedures was $573 \pm 77 \mathrm{nmol} / \mathrm{L}$ and 1 hour and 24-hours after operations were $847 \pm 63$ and $529 \pm 52$ respectively.

In the elective surgical procedures, the preoperative mean serum cortisol concentration was almost similar to that of healthy control. But in the emergency surgical procedures, it was significantly increased $(\mathrm{P}<0.05)$ compared to that of healthy control (Table - II).

Table-II: Statistical analysis of results shown in this table

\begin{tabular}{lc}
\hline Groups & P values \\
\hline I vs. IIA & $0.350^{\mathrm{NS}}$ \\
I vs. IIB & $0.000^{* * *}$ \\
I vs. IIC & $0.014^{*}$ \\
I vs. IIIA & $0.015^{*}$ \\
I vs. IIIB & $0.000^{* * *}$ \\
I vs. IIIC & $0.008^{* *}$ \\
IIA vs. IIIA & $0.045^{*}$ \\
IIB vs. IIIB & $0.039^{*}$ \\
IIC vs. IIIC & $0.263^{\mathrm{NS}}$ \\
IIA vs. IIB & $0.000^{* * *}$ \\
IIA vs. IIC & $0.138^{\mathrm{NS}}$ \\
IIB vs. IIC & $0.000^{* * *}$ \\
IIIA vs. IIIB & $0.000^{* * *}$ \\
IIIA vs. IIIC & $0.415^{\mathrm{NS}}$ \\
IIIB vs. IIIC & $0.000^{* * *}$ \\
\hline
\end{tabular}

Data was analyzed by pair and unpair ' $\mathrm{t}$ ' test. $*=\mathrm{P}<0.05, * *=\mathrm{P}<0.01, * * *=\mathrm{P}<0.001 \mathrm{NS}=$ Not significant; $\mathrm{df}=$ Degree of freedom

$\mathrm{P}=$ Probability. Group I = Healthy controls; Group II = Patient undergoing elective surgery; Group III = Patient undergoing emergency surgery. $\mathrm{A}=$ Preoperative; $\mathrm{B}=1$-hour post-operative; $\mathrm{C}=24$-hour post-operative.

One hour after operations, the mean serum cortisol concentrations were significantly increased in both groups of patients compared

J Bangladesh Soc Physiol. 2007 Dec;(2): 28-33. 
to their preoperative base levels and also healthy control. But the magnitude of rise was significantly greater $(\mathrm{P}<0.05)$ in emergency surgical procedures compared to that of elective surgical procedures. (Table - II).

Again compared to the healthy control, the 24hours postoperative serum cortisol concentrations were increased both in elective $(\mathrm{P}<0.05)$ and emergency $(\mathrm{P}<0.01)$ surgical procedures. Though higher serum cortisol concentrations over their preoperative basal levels were still observed 24 hours after operations, the differences were not statistically significant (Table - II). There was a non-significant rise in serum cortisol concentration 24 hours after operations in emergency surgical procedures compared to that of elective ones.

Table - III : Mean $( \pm$ SE) duration of operation and stress severity score

\begin{tabular}{lcc}
\hline Groups & $\begin{array}{c}\text { Group II } \\
(\mathrm{n}=20)\end{array}$ & $\begin{array}{c}\text { Group III } \\
(\mathrm{n}=20)\end{array}$ \\
\hline $\begin{array}{l}\text { Duration of } \\
\text { operation (minutes) }\end{array}$ & $73.50 \pm 4.17$ & $89.00 \pm 10.52$ \\
$\begin{array}{l}\text { Stress severity } \\
\text { score }\end{array}$ & $12.20 \pm 0.36$ & $10.60 \pm 0.64$ \\
\hline
\end{tabular}

Group II = Patients undergoing elective surgery; Group III = Patients undergoing emergency surgery; $\mathrm{n}=$ Total number of patients.

Table III shows that in elective surgical cases the mean duration of operations and stress severity score were $73.50 \pm 4.17$ minutes and $12.20 \pm 0.36$ respectively. These values in emergency surgical cases were $89.00 \pm 10.52$ minutes and $10.60 \pm 0.64$ respectively.

Significant positive correlation was observed between serum cortisol concentrations and stress severity scores in both elective $(r=0.478, \mathrm{P}<$ $0.05)$ and emergency $(\mathrm{r}=0.720, \mathrm{P}<0.001)$ group of patients 1-hour after operations (Table IV).
Table-IV: Shows regression analysis of serum cortisol concentrations with stress severity score $(n=40)$

\begin{tabular}{lcccc}
\hline Groups & & & \multicolumn{2}{c}{ Serum cortisol } \\
& & $\mathrm{n}$ & $\mathrm{r}$ & $\mathrm{p}$ values \\
\hline Group II & IIB & 20 & 0.478 & $0.033^{*}$ \\
& IIC & 20 & -0.004 & $0.987^{\mathrm{NS}}$ \\
Group III & IIIB & 20 & 0.720 & $0.000^{* * *}$ \\
& IIIC & 20 & 0.492 & $0.027^{*}$ \\
\hline
\end{tabular}

$*=\mathrm{P}<0.05 ; * * *=\mathrm{P}<0.001 \mathrm{NS}=$ Not significant. Group II = Patient undergoing elective surgery; Group III = Patient undergoing emergency surgery. A = Preoperative; $\mathrm{B}=1$-hour post-operative; $\mathrm{C}=24$-hour post-operative. $\mathrm{n}=$ Total number of patients; $\mathrm{r}=$ average value of two regression coefficients;

Again, the relationship between serum cortisol concentrations and duration of operations in emergency surgical procedures was positive and also statistically significant $(\mathrm{r}=0.571, \mathrm{P}<0.01)$. Though it was positively correlated but statistically not significant in elective surgical cases (Table-V).

Table - V: Shows regression analysis of serum cortisol concentrations with duration of operations $(n=40)$

\begin{tabular}{lcccc}
\hline Groups & $\mathrm{n}$ & $\mathrm{r}$ & $\mathrm{p}$ values & \\
\hline Group II & IIB & 20 & 0.440 & $0.052^{\mathrm{NS}}$ \\
& IIC & 20 & 0.168 & $0.478^{\mathrm{NS}}$ \\
Group III & IIIB & 20 & 0.571 & $0.009^{* *}$ \\
& IIIC & 20 & 0.313 & $0.179^{\mathrm{NS}}$ \\
\hline
\end{tabular}

** $=\mathrm{P}<0.01$; NS = Not significant. Group II = Patient undergoing elective surgery; Group III = Patient undergoing emergency surgery. $\mathrm{A}=$ Pre-operative; $\mathrm{B}$ = 1-hour post-operative; $\mathrm{C}=24$-hour post-operative. $\mathrm{n}=$ Total number of patients; $\mathrm{r}=$ average value of two regression coefficients; $\mathrm{P}=$ Probability. 


\section{Article}

\section{Discussion}

The present study has been conducted to investigate the effects of surgical stress on serum levels of cortisol and to find out any difference in hormonal response pattern between elective and emergency surgical procedures.

In the elective surgical cases the mean serum cortisol concentration was significantly increased ( $\mathrm{P}<0.001)$ 1-hour after operation compared to that of their preoperative level. Some investigators of different countries also made similar observations ${ }^{6-13}$. Twenty four hours after operations the mean serum cortisol concentration was decreased significantly $(\mathrm{P}<0.001)$ from its1hour post operative mean value and returned almost to the preoperative base line. Hagen et al. ${ }^{13}$ also reported similar findings. On the contrary, significantly increased serum cortisol concentrations 24-hour after operations compared to their preoperative values were found. $6,9,12,14$

In the emergency surgical procedures of the present study a significantly increased serum cortisol concentration was observed even before starting of operations compared to the healthy controls. One hour after operations the concentration was increased further over their preoperative level. The 24-hour post operative mean concentration was decreased significantly from their 1-hour postoperative level and returned to their preoperative base level. But this mean value was still significantly higher than that of healthy control.

The serum cortisol concentrations were increased both in elective and emergency surgical cases but the magnitude of rise was more marked in emergency ones. Significantly higher levels of serum cortisol were observed in emergency group of patients in comparison to that of elective cases both preoperatively and 1-hour after operations. However, cortisol concentration was only nonsignificantly higher in 24-hour postoperative mean.
Surgical Stress and Cortisol

The actual mechanism involved for this raised serum cortisol concentrations in emergency surgical patients before operations and after surgery and anaesthesia-induced stress in both elective and emergency surgical cases has not yet been fully confirmed. It has been suggested that surgery and trauma result in a physiologic response characterized by increased energy demands ${ }^{15}$. To meet the extra demand, there is shift of substrate from storage to various central organs and traumatized tissues. Higher concentration of cortisol during stress facilitates the substrate mobilization ${ }^{15}$.

During abdominal surgery, cortisol response is released largely through autonomic afferent pathways from intraperitoneal organs 13,15 . Somatic sensory pathways are not the major release mechanism of cortisol response to surgery. Increased cortisol production is secondary to preceding increase in ACTH secretion ${ }^{16}$. Afferent impulses to hypothalamus via the nociceptive pathways and reticular formation trigger ACTH secretion in response to injury ${ }^{17}$.

A number of factors may influence the response due to stress induced by surgery and anaesthetic procedures. These include preoperative fear and anxiety, starvation, type and duration of operation, haemorrhage, anaesthetic regimen etc. But severity of stress is considered to be the major regulator of hormonal responses ${ }^{15}$. In elective surgical cases, stress severity scores correlated significantly with rise of cortisol 1-hour postoperatively but not 24-hours after operations. Similar observations have also been reported by some group of investigators of different countries. ${ }^{2,4-6}$ This apparent relationship may be due to release of progressively higher concentration of ACTH with increasing severity of stress. A linear relationship between the log of concentration of ACTH and increasing cortisol secretion has also been suggested ${ }^{17}$.

J Bangladesh Soc Physiol. 2007 Dec;(2): 28-33. 
In this study, emergency surgical cases demonstrated a significant relationship between duration of operations and rise of cortisol 1-hour postoperatively. On the other hand, the hormonal responses in elective surgical procedures were not affected by duration of operations. Similar observation was also reported by other researchers 11, 18.

\section{Conclusion}

The serum cortisol concentrations were increased both in elective and emergency surgical cases, but the magnitude of increase was more marked in emergency ones. In the emergency surgical patients, already existing stress due to pain, inflammation and haemodynamic disturbances may be the cause of higher serum cortisol concentration. Autonomic afferent discharge from inflamed peritoneum and intraperitoneal organs may be the major release mechanism for cortisol.

\section{Author Affiliations}

1. Major S M Selimuzzaman, MBBS, M Phil, Assistant Professor of Physiology, Armed Forces Medical College, Dhaka Cantonment, Bangladesh, Email: sm_zaman895@hotmail.com

2. Prof Noorzahan Begum, MBBS, M Phil, Chairman, Department of Physiology, BSMMU, Shahbag, Dhaka, Bangladesh

3. Dr Nadira Islam, MBBS, M Phil, PhD, Professor of Physiology, BSMMU, Shahbag, Dhaka, Bangladesh

4. Dr Shelina Begum, MBBS, M Phil, Associate Professor of Physiology, BSMMU, Shahbag, Dhaka, Bangladesh

\section{References}

1. Keele CA, Neil E, Joles N, editors. Endocrine glands. In: Samson Wright's Applied Physiology. $13^{\text {th }}$ ed. Delhi: Oxford University Press; 1982, pp 497 - 562

2. Alberti KGMM, Batstone GF, Foster KJ, Johnston DG. Relative role of various hormones mediating the metabolic response to injury. J.P.E.N. 1980; 4: 141146.

3. Johnston IDA. Endocrine aspects of metabolic response to surgical operation. Ann R Coll Surg Engl. 1964; 35: 270-286.

4. Clarke R S J. The hyperglycemic response to different types of surgery and anaesthesia. Br J Anaesth. 1970; 42: 45-53.
5. Foster K J, Alberti K G M M, Binder C et al. Lipid metabolites and nitrogen balance after abdominal surgery in man. Br J Surg. 1979; 66: 242-245.

6. Chernow B, Alexander HR, Smallridge RC. Hormonal response to graded surgical stress. Arch Intern Med 1987; 147: 1273-8.

7. Anand K J S, Green A A. Measuring surgical stress in newborn infants. J Pediatr Surg 1988; 23 (4): 297-305.

8. Lush D, Thorpe J N, Richardson D J, Bowen D J. The effect of epidural analgesia on adrenocortical response to surgery. Br J Anaesth 1972; 44: 1169-72.

9. Kehlet H, Brandt M R, Hansen A P, Alberti K G M M. Effect of epidural analgesia on metabolic profiles during and after surgery. Br J Surg. 1979; 66: 543-6.

10. Masala A, Satta C, Alagna S. Effect of clonidine on stress-induced cortisol release in man during surgery. Pharmacol Res Commun 1985; 17 (3): 293-8.

11. Khilnani P, Munoz R, Salem M, Gelb C, Todres I D, Chernow B. Hormonal response to surgical stress in children. J Pediatr Surg 1993;24(1):1-4.

12. Oyama T, Toyota M, Shinozaki Y, Kudo T. Effects of morphine and ketamine anaesthesia and surgery on plasma concentrations of luteinizing hormone, testosterone and cortisol in man. Br J Anaesth 1977; 49: $983-90$

13. Hagen C, Brandt M R, Kehlet H. Prolactin, LH, FSH, $\mathrm{GH}$ and cortisol response to surgery and the effect of epidural analgesia. Acta Endocrinologica 1980; 94: 151-4.

14. Brandt M, Korshin K, Prange HA. Influence of morphine anaesthesia on endocrine metabolic response to open heart surgery. Acta Anaesthesiol Scand 1978; 22: $400-5$.

15. Kehlet H, Brandt M R, Rem J. Role of neurogenic stimuli in mediating the endocrine-metabolic response to surgery. J Parenteral Enteral Nutr 1980; 4(2): $152-6$.

16. Oyama T, Takiguchi M. Plasma levels of ACTH and cortisol in man during halothane anaesthesia and surgery. Anesth Analg (Cleve) 1970; 49: 363.

17. Ganong W F, In: Review of Medical Physiology. $21^{\text {st }}$ ed. USA: Prentice - Hall International Inc., 2001, pp 359-384

18. Boninsegni R, Salerno R, Giannotti P. Effects of surgery and epidural or general anaesthesia on testosterone, 17-hydroxyprogesterone and cortisol plasma levels in prepubertal boys. J Steroid Biochem 1983; 19(6): 1783-7. 